\title{
Assessment of Patients with Takayasu Arteritis in Routine Practice with Indian Takayasu Clinical Activity Score
}

\author{
Fatma Alibaz-Oner, Sibel Z. Aydin, Servet Akar, Kenan Aksu, Sevil Kamali, Eftal Yucel, Omer \\ Karadag, Huseyin Ozer, Sedat Kiraz, Fatos Onen, Murat Inanc, Gokhan Keser, \\ Nurullah Akkoc, and Haner Direskeneli
}

\begin{abstract}
Objective. To assess the Indian Takayasu Clinical Activity Score (ITAS2010) in followup of Takayasu arteritis (TA).

Methods. ITAS2010 forms were filled in prospectively $(\mathrm{n}=144)$. Clinical activity was assessed with physician's global assessment (PGA) and criteria defined by Kerr, et al.

Results. ITAS2010 was significantly higher in patients with active disease. Total agreement between ITAS2010 and PGA was 66.4\%, and between ITAS2010 and Kerr, et al was 82.8\%. During followup, 14 of 15 patients showing vascular progression with imaging were categorized as having inactive disease according to ITAS2010.

Conclusion. ITAS2010 was discriminatory for activity during the followup, but the agreement between PGA and ITAS2010 was moderate. Future work should include the incorporation of advanced vascular imaging and demonstration of ITAS2010 as a scalable measure and not simply a dichotomous measure of activity/flare versus remission. (First Release July 1 2015; J Rheumatol 2015;42:1443-7; doi:10.3899/jrheum.140817)
\end{abstract}

Key Indexing Terms:

TAKAYASU ARTERITIS

ITAS2010

ACTIVITY

ASSESSMENT

Takayasu arteritis (TA) is a rare, chronic, large vessel vasculitis that predominantly affects the aorta, its major branches, and the pulmonary arteries ${ }^{1}$. Assessment of activity in TA is difficult and efforts to develop validated tools for research and clinical practice are continuing. The simple definition of "active disease" that was first defined by Kerr, et al (presence of constitutional symptoms, new bruits, acute-phase response, or new angiographic features) is commonly applied in studies of $\mathrm{TA}^{2}$. Although designed to apply to all vasculitides, the Birmingham Vasculitis Activity Score (BVAS) is validated for use only in small- and medium-vessel vasculitis. However, because most of the 11 organ systems in BVAS are not involved in TA, the value of BVAS is limited ${ }^{3}$. The disease extent index for TA (DEI.Tak) is an attempt to derive an activity/extent index based on the BVAS. DEI.Tak assesses activity/extent with only clinical findings, without a requirement for imaging techniques, but is not widely accepted $\mathrm{d}^{4,5}$.

Misra, et al developed and validated a new composite index - the Indian Takayasu Clinical Activity Score (ITAS2010) - for the clinical assessment of TA. ITAS2010 was again developed from the BVAS and is also weighted for vascular items ${ }^{6}$. In our study, we aimed to investigate ITAS2010 in a second population for the routine clinical
From the Department of Rheumatology Istanbul, School of Medicine, Marmara University; Department of Rheumatology, Koç University; Department of Rheumatology, Faculty of Medicine, Istanbul University, Istanbul; Department of Rheumatology, School of Medicine, Dokuz Eylul University; Department of Rheumatology, School of Medicine, Ege University, Izmir; Department of Rheumatology, School of Medicine, Baskent University; Department of Rheumatology, School of Medicine, Hacettepe University, Ankara, Turkey; Department of Rheumatology, School of Medicine, Cukurova University, Adana, Turkey.

F. Alibaz-Oner, MD, Specialist in Rheumatology, Department of Rheumatology, School of Medicine, Marmara University; S.Z. Aydin, MD, Associate Professor of Rheumatology, Department of Rheumatology, Koc University; S. Akar, MD, Professor of Rheumatology, Department of Rheumatology, School of Medicine, Dokuz Eylul University; K. Aksu, MD, Professor of Rheumatology, Department of Rheumatology, School of Medicine, Ege University; S. Kamali, MD, Professor of Rheumatology, Department of Rheumatology, Faculty of Medicine, Istanbul University; E. Yucel, MD, Professor of Rheumatology, Department of Rheumatology, School of Medicine, Baskent University; O. Karadag, MD, Associate
Professor of Rheumatology, Department of Rheumatology, School of Medicine, Hacettepe University; H. Ozer, MD, Professor of Rheumatology, Department of Rheumatology, School of Medicine, Cukurova University; S. Kiraz, MD, Professor of Rheumatology, Department of Rheumatology, School of Medicine, Hacettepe University; F. Onen, MD, Professor of Rheumatology, Department of Rheumatology, School of Medicine, Dokuz Eylul University; M. Inanc, MD, Professor of Rheumatology, Department of Rheumatology, Faculty of Medicine, Istanbul University; G. Keser, MD, Professor of Rheumatology, Department of Rheumatology, School of Medicine, Ege University; N. Akkoc, MD, Professor of Rheumatology, Department of Rheumatology, School of Medicine, Dokuz Eylul University; H. Direskeneli, MD, Professor of Rheumatology, Department of Rheumatology, School of Medicine, Marmara University.

Address correspondence to Dr. F. Alibaz-Oner, Department of Rheumatology, Marmara University Hospital, Fevzi Çakmak Mahallesi, Mimar Sinan Cad., No: 41, Ust-Kaynarca, Pendik, Istanbul, Turkey. E-mail:falibaz@gmail.com

Accepted for publication February 24, 2015.

Personal non-commercial use only. The Journal of Rheumatology Copyright @ $\odot 2015$. All rights reserved 
followup of patients with TA from Turkey to externally validate it as an assessment tool using physician's global assessment (PGA) as the gold standard.

\section{MATERIALS AND METHODS}

The study included 144 patients (age $40.9 \pm 12.3 \mathrm{yrs}$, female/male: $128 / 16$ ) fulfilling the American College of Rheumatology (ACR) criteria for $\mathrm{TA}^{7}$ and followed in 8 centers in Turkey. The eligibility criteria for our study were the diagnosis of TA according to the ACR 1990 criteria, having sufficient data on acute-phase reactants (APR), vascular symptoms, physical examination, and PGA during the visit. The mean disease duration was 8.3 years $(0-40)$. ITAS2010 forms were filled in routine visits prospectively, with intervals of at least 4-6 months, by including only new or worsening symptoms within the past 3 months, as suggested. In total, 289 visits from 144 patients were included. APR and progressions in imaging modalities (whenever available) were recorded. In experienced centers in Turkey, imaging for the followup of TA was performed as clinically required to assess active disease. Different imaging modalities according to the preferential approaches of individual centers were chosen. Positive imaging was defined as development of a new vascular involvement, progression in luminal vascular lesions, or increased vascular uptake in 18F-fluorodeoxyglucose positron emission tomography (FDG-PET).

Active disease by PGA was defined by the attending physician as any new symptom that is associated with disease activity, such as malaise, weight loss, myalgia, dizziness, or claudication; new signs, such as hypertension, syncope, or bruits; or any elevation in acute-phase responses. PGA assessments were performed before imaging results were present.

ITAS2010 with APR (ITAS-A) was calculated combining ITAS2010-A [either erythrocyte sedimentation rate (ESR) or C-reactive protein (CRP)], as suggested by Misra, et $a l^{6}$. ITAS-ESR was calculated as ITAS plus 0 for $<20$, 1 for $21-39,2$ for $40-59$, and 3 for $>60 \mathrm{~mm} / \mathrm{h}$ by Westergren method. ITAS-CRP was calculated as ITAS plus 0 for $\leq 5,1$ for $6-10,2$ for $11-20$, and 3 for $>20 \mathrm{mg} / 1^{6}$. If both ITAS-ESR and ITAS-CRP were available, the higher score was accepted as ITAS-A. Active disease was defined as $>1$ for ITAS2010 and $>4$ for ITAS-A subsets. Patients were also evaluated by activity defined by Kerr, et $a l^{2}$. PGA was used as the gold standard activity definition in our study; however, if available, activity defined according to Kerr, et al was also used.

During the study period, oral methylprednisolone was given to 133 patients (91.7\%). As additional immunosuppression (IS), 49 patients (34\%) received azathioprine, $77(53.5 \%)$ received methotrexate, $10(6.9 \%)$ received leflunomide, $4(2.8 \%)$ received infliximab, and $1(0.7 \%)$ received mycophenolate mofetil therapy.

The study was performed according to the Declaration of Helsinki and all subjects gave informed consent before participation. Statistical data were performed with Statistical Package for the Social Sciences 16.0 (SPSS) program. Results were expressed as means and SD or as median (minimum-maximum) according to the distribution of data. Mann-Whitney $\mathrm{U}$ test, independent samples Student $\mathrm{t}$ test, Wilcoxon test, and chi-square test were used for comparisons of data. Spearman correlation test was used to analyze correlations. The percentage of exact agreement was calculated for clinical activity assessment tools. Kappa statistics (unweighted $\kappa$ for dichotomous assessment) were also used for the assessment of convergence between ITAS2010, ITAS-A, Kerr, et al's criteria ${ }^{2}$, and PGA.

\section{RESULTS}

Among the 338 visits of 144 patients, 289 visits were included in our study and 49 were excluded because of insufficient information about the presence and the duration of current symptoms and signs. According to PGA, patients were categorized with active disease in 129 visits (44.6\%), whereas active disease was present in only 68 visits $(23.5 \%)$ according to ITAS2010. In 140 visits, Kerr, et al activity definition was available and in 18 of these (12.9\%), patients were categorized with active disease. In 8 of these 18 patients, imaging was available and showed a radiologic progression. ITAS2010, ITAS-ESR, ITAS-CRP, and APR were significantly higher in patients with active disease compared with those with inactive disease, defined with both PGA and Kerr, et al (Table 1). Distribution of ITAS2010 according to the PGA is given in Figure 1. ITAS2010 significantly correlated with both ESR $(r=0.230, p<0.001)$ and CRP $(r=0.238, p<0.001)$. As expected, ITAS2010 also significantly correlated with ITAS-ESR and ITAS-CRP $(r=$ $0.975, \mathrm{p}<0.001$ and $\mathrm{r}=0.969, \mathrm{p}<0.001$, respectively). While PGA significantly correlated with both ESR $(r=0.476$, $\mathrm{p}<0.001)$ and CRP $(\mathrm{r}=0.292, \mathrm{p}<0.001)$, Kerr, et al showed a weak correlation only with ESR $(r=0.173, p=0.04)$.

The total agreement between ITAS2010 and PGA was $66.4 \%(\kappa=0.29)$, and between ITAS2010 and Kerr, et al, it was $82.8 \%(\kappa=0.35)$. The total agreement between PGA and Kerr, et al was also moderate $(70.7 \%, \kappa=0.28)$. When APR was added, total agreement between PGA and ITAS-A did not improve much $(67 \%, \kappa=0.29)$. However, agreement was better with Kerr, et al $(86.3 \%, \kappa=0.35)$.

A step-up regimen increasing the IS dose or changing/ adding new agents was chosen in 45 patients during the followup period. While 43 of these patients had active disease according to PGA (95.5\%), only 33 patients had active disease with ITAS2010 (73.3\%).

Forty-three patients were evaluated with imaging in the followup period [6 with FDG-PET, 23 with magnetic resonance (MR) angiography, 8 with vascular Doppler ultrasonography, 3 with computerized tomography (CT) angiography, and 3 with conventional angiography]. Vascular progression was observed in 15 patients (34.9\%) with imaging. Only 1 patient showing progression with imaging was categorized as having inactive disease with PGA. However, 14 of 15 patients showing progression with imaging were categorized as having inactive disease according to ITAS2010, but accepted to be active with PGA. Imaging was significantly compatible with PGA ( $<<0.001)$, but not with ITAS2010 $(p=0.953)$ for active disease (Table 2).

We also analyzed the data with an equal number of visits per patient to prevent any bias attributable to unequal visit numbers. When only 1 visit from each patient was analyzed $(n=144)$, ITAS2010, ITAS-ESR, ITAS-CRP, and APR were again significantly higher in patients with active disease compared with those with inactive disease, defined with both PGA and Kerr, et al (Supplementary Table 3 is available from the authors on request). The total agreement between ITAS2010 and PGA was $68 \%(\kappa=0.336)$, and between ITAS2010 and Kerr, et al was $86.5 \%(\kappa=0.622)$. The total agreement between PGA and Kerr, et al was also good (85\%, $\kappa=0.660$ ). When APR was added, total agreement between PGA and ITAS-A did not improve $(66.5 \%, \kappa=0.3)$. When

Personal non-commercial use only. The Journal of Rheumatology Copyright @ 2015 . All rights reserved. 
Table 1. Comparison of ITAS 2010, ITAS-ESR, and ITAS-CRP scores and APR between patients with active and inactive disease, defined according to PGA and Kerr, $e t a l^{2}$ in all visits. Values are mean $\pm \mathrm{SD}$ [median (IQR)] or mean $\pm \mathrm{SD}$ unless otherwise specified.

\begin{tabular}{|c|c|c|c|c|c|c|}
\hline Variables & Active, $\mathrm{n}=129$ & $\begin{array}{c}\text { PGA } \\
\text { Inactive, } n=160\end{array}$ & $\mathrm{p}$ & Active, $\mathrm{n}=18$ & $\begin{array}{c}\text { Kerr, } \text { et al } \\
\text { Inactive, } \mathrm{n}=122\end{array}$ & $\mathrm{p}$ \\
\hline ITAS2010 & $3.1 \pm 5.1[0(0-24)]$ & $0.5 \pm 1.7[0(0-15)]$ & $<0.001$ & $5.6 \pm 6.8[2(0-19)]$ & $0.8 \pm 2.1[0(0-15)]$ & $<0.001$ \\
\hline ITAS-ESR & $4.3 \pm 5.1[2(0-24)]$ & $0.9 \pm 2[0(0-18)]$ & $<0.001$ & $5.9 \pm 5.6[3(0-18)]$ & $1.6 \pm 2.4[1(0-17)]$ & $<0.001$ \\
\hline $\mathrm{ESR}, \mathrm{mm} / \mathrm{h}$ & $35.9 \pm 21$ & $17.8 \pm 12.4$ & $<0.001$ & $37.7 \pm 18.4$ & $26.5 \pm 18.2$ & 0.025 \\
\hline CRP, mg/l & $13.2 \pm 19.2$ & $4.9 \pm 5.6$ & $<0.001$ & $12.5 \pm 13.9[11(0.1-54.3)]$ & $7.3 \pm 9.6[3.4(0.2-58)]$ & 0.06 \\
\hline
\end{tabular}

ITAS2010: Indian Takayasu Clinical Activity Score; ESR: erythrocyte sedimentation rate; CRP: C-reactive protein; APR: acute-phase reactants; PGA: physician's global assessment; IQR: interquartile range; n: number of visits.
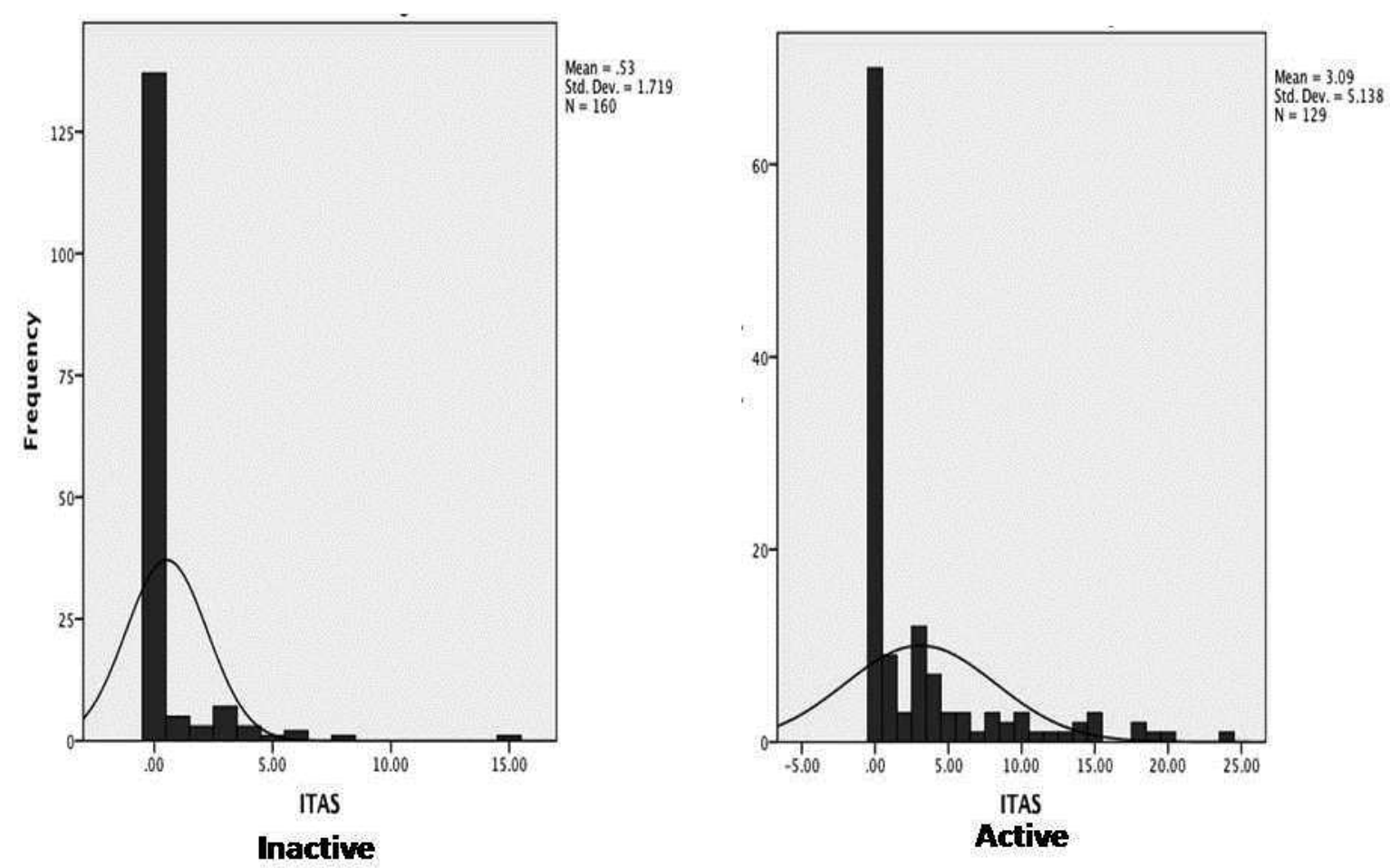

Figure 1. Distribution of ITAS2010 score according to physician's global assessment.

Table 2. Distribution of patients with active and inactive disease according to PGA and ITAS2010 in groups developing vascular progression with imaging. Values are $n$.

\begin{tabular}{llcc}
\hline Variables & & Progression+ & Progression- \\
\hline \multirow{2}{*}{ ITAS2010 } & Active & 1 & 2 \\
\multirow{2}{*}{ PGA } & Inactive & 14 & 26 \\
& Active & 14 & 8 \\
& Inactive & 1 & 20
\end{tabular}

PGA: physician's global assessment; ITAS2010: Indian Takayasu Clinical Activity Score.

the 170 visits of 85 patients ( 2 visits for each patient) were analyzed, results were again similar to the whole group
(Supplementary Table 4 is available from the authors on request). The total agreement between ITAS2010 and PGA was $66.4 \%(\kappa=0.326)$, and between ITAS2010 and Kerr, et $a l$ was $79.7 \%$ ( $\kappa=0.333)$. The total agreement between PGA and Kerr, et al was also good $(78.7 \%, \kappa=0.508)$. When APR was added, total agreement between PGA and ITAS-A also did not improve $(65.6 \%, \kappa=0.311)$.

\section{DISCUSSION}

There is currently no gold standard for the assessment of disease activity in TA. PGA is widely used as the assessment tool in routine clinical practice and is based on clinical features, APR, and imaging abnormalities that are also reflected in the criteria defined by Kerr, et $a l^{2,8}$. Assessment 
of APR is frequently advocated for disease assessment in TA, despite being shown to be neither sensitive nor specific enough to monitor disease activity ${ }^{9}$. Data coming from the new studies support that imaging with MR angiography and FDG-PET is also promising ${ }^{1}$.

ITAS2010 and the composite score ITAS-A, including clinical features plus APR, are the first validated assessment tools for monitoring activity in $\mathrm{TA}^{6}$. In our present study, ITAS2010 had a discriminatory value in all visits for active disease, compatible with Misra, et $a l^{6}$. ITAS-ESR and ITAS-CRP scores were also significantly higher in patients with active disease and a significant correlation was also observed between APR and ITAS2010 in all visits. Misra, et al suggested that ITAS-A was comparable with ITAS-2010 regarding performance, but remained elevated in the followup period in spite of clinical response to induction therapy. Although CRP and ESR had weak correlations with ITAS2010, the authors made a further attempt to incorporate APR to the score (ITAS2010-A) by adding an extra 1-3 points for elevated ESR or CRP. This change resulted in higher ITAS2010-A scores in patients with both active and inactive disease. Further, when "response to change" was assessed by ITAS2010-A, patients still had a mean score of 4 at the third visit when they were deemed to be clinically inactive with PGA. That items on the ITAS2010 are still present even during apparent remission is problematic and illustrates the substantial difficulty in differentiating activity from damage because of nonvasculitis-related problems in $\mathrm{TA}^{10}$.

In our study, the agreement between PGA and ITAS2010 was observed to be moderate (66.4\%), similar to the original study. The total agreement between PGA and ITAS-A was not much better $(67.1 \%)$. Both ITAS2010 and ITAS-A have better correlations with Kerr, et al (82-86\%). ITAS2010 is based primarily on physical examination for new vascular signs. However, Grayson, et al, who investigated the association between physical examination and imaging data, showed that individual physical examination findings had poor sensitivity (14-50\%), and even when used in combination, at least $30 \%$ of arteriographic lesions were missed ${ }^{11}$. Further in this context, ITAS2010 requires a score $>1$ and ITAS-A $>4$ as cutoffs for positivity, which might be too high for the assessment of "low disease activity." Physicians" general sense of "active disease," such as constitutional symptoms (malaise, weight loss) or dizziness, and some clinical features, such as systolic hypertension, score only 1 point in ITAS2010 and are below the threshold for active disease. Similarly, isolated APR elevations (1-3 points) without clinical features are not sufficient to define active disease by ITAS-A, whereas they may lead the physician for new imaging. In support of our results, we have recently demonstrated that PET was positive in 13 of 14 patients investigated for isolated APR without any clinical symptom or sign for at least 3 months ${ }^{12}$. Therefore, imaging methods such as CT and MR angiography that show both lumen changes and vessel wall enhancement and PET demonstrating vessel wall activity seem to support physicians' final decisions on therapy changes ${ }^{13,14}$. ITAS2010 was used in open-label case series of biological agents such as anti-tumor necrosis factor- $\alpha$ and antiinterleukin 6 therapies in $\mathrm{TA}^{15}$. However, because only 2 assessments were reported with the baseline visit highly elevated, whether ITAS2010 will be a suitable clinical tool to reflect response to biological treatments in longterm followup still needs to be clarified ${ }^{16}$.

Major limitations of our study are the short followup duration and limited imaging data in our patient group. Preference of different imaging modalities according to individual protocols of study centers is also another limitation. In a slowly progressive disease such as TA, more followup duration is necessary to show individual changes of an assessment tool in remission and relapse phases. Similarly, because PGA is possibly insufficient as the standard for current activity, imaging is also necessary for longterm comparisons. However, routine imaging, without symptoms or signs of clinical activity, is currently not the usual practice in most experienced centers in Turkey.

ITAS2010 seems a practical assessment tool, taking only a few minutes in daily practice. Both ITAS2010 and ITAS-A had discriminatory value for active disease during the followup, but the agreement between PGA and ITAS2010/ITAS-A is observed to be moderate in our study. Future work on ITAS should include the incorporation of advanced vascular imaging, demonstration of the instrument's use as a meaningfully scalable measure and not simply a dichotomous measure of activity/flare versus remission, and validation of the tool in different cohorts by other investigators.

\section{REFERENCES}

1. Alibaz-Oner F, Aydin SZ, Direskeneli H. Advances in the diagnosis, assessment and outcome of Takayasu's arteritis. Clin Rheumatol 2013;32:541-6.

2. Kerr GS, Hallahan CW, Giordano J, Leavitt RY, Fauci AS, Rottem M, et al. Takayasu arteritis. Ann Intern Med 1994;120:919-29.

3. Mukhtyar C, Lee R, Brown D, Carruthers D, Dasgupta B, Dubey S, et al. Modification and validation of the Birmingham Vasculitis Activity Score (version 3). Ann Rheum Dis 2009;68:1827-32.

4. Sivakumar MR, Misra RN, Bacon PA. The Indian perspective of Takayasu arteritis and development of a disease extent index (DEI.Tak) to assess Takayasu arteritis. Rheumatology 2005;44 Suppl 3:iii6-7.

5. Aydin SZ, Yilmaz N, Akar S, Aksu K, Kamali S, Yucel E, et al. Assessment of disease activity and progression in Takayasu's arteritis with Disease Extent Index-Takayasu. Rheumatology 2010;49:1889-93.

6. Misra R, Danda D, Rajappa SM, Ghosh A, Gupta R, Mahendranath $\mathrm{KM}$, et al; Indian Rheumatology Vasculitis (IRAVAS) group. Development and initial validation of the Indian Takayasu Clinical Activity Score (ITAS2010). Rheumatology 2013;52:1795-801.

7. Arend WP, Michel BA, Bloch DA, Hunder GG, Calabrese LH, Edworthy SM, et al. The American College of Rheumatology 1990 criteria for the classification of Takayasu arteritis. Arthritis Rheum 1990;33:1129-34.

Personal non-commercial use only. The Journal of Rheumatology Copyright (C 2015. All rights reserved. 
8. Direskeneli H, Aydin SZ, Merkel PA. Assessment of disease activity and progression in Takayasu's arteritis. Clin Exp Rheumatol 2011;29 Suppl 64:S86-91

9. Mason JC. Takayasu arteritis-advances in diagnosis and management. Nat Rev Rheumatol 2010;6:406-15.

10. Direskeneli H, Aydin SZ, Merkel PA. Disease assessment in Takayasu's arteritis. Rheumatology 2013;52:1735-6.

11. Grayson PC, Tomasson G, Cuthbertson D, Carette S, Hoffman GS, Khalidi NA, et al; Vasculitis Clinical Research Consortium. Association of vascular physical examination findings and 80 arteriographic lesions in large vessel vasculitis. J Rheumatol 2012;39:303-9.

12. Alibaz-Oner F, Dede F, Ones T, Turoglu HT, Direskeneli H. Patients with Takayasu's arteritis having persistent acute-phase response usually have an increased major vessel uptake by 18F-FDG-PET/CT. Mod Rheumatol 2015 Mar 12:1-4 (E-pub ahead of print).
13. Kobayashi $Y$, Ishii $K$, Oda K, Nariai T, Tanaka Y, Ishiwata K, et al. Aortic wall inflammation due to Takayasu arteritis imaged with 18F-FDG PET coregistered with enhanced CT. J Nucl Med 2005;46:917-22.

14. Lee KH, Cho A, Choi YJ, Lee SW, Ha YJ, Jung SJ, et al. The role of (18) F-fluorodeoxyglucose-positron emission tomography in the assessment of disease activity in patients with Takayasu arteritis. Arthritis Rheum 2012;64:866-75.

15. Youngstein T, Peters JE, Hamdulay SS, Mewar D, Price-Forbes A, Lloyd M, et al. Serial analysis of clinical and imaging indices reveals prolonged efficacy of TNF- $\alpha$ and IL- 6 receptor targeted therapies in refractory Takayasu arteritis. Clin Exp Rheumatol 2014;32 Suppl 82:S11-8.

16. Salvarani C, Magnani L, Catanoso M, Pipitone N, Versari A, Dardani L, et al. Tocilizumab: a novel therapy for patients with large-vessel vasculitis. Rheumatology 2012;51:151-6. 